\title{
EN BÚSQUEDA DE UNA EVIDENCIA RAZONABLE DE LAS CREENCIAS RELIGIOSAS
}

\author{
Fredy Humberto Castañeda Vargas, S.J." \\ doi:10.11144/Javeriana.uph33-66.berc
}

\begin{abstract}
RESUMEN
Este artículo presenta la cuestión de si las creencias religiosas son o no razonables, es decir, si tienen o no una evidencia razonable que las sustente. El interés no es comprobar la existencia de Dios, sino simplemente saber si el lenguaje religioso como tal tiene o no sentido. Para esto, primero veremos la concepción de la creencia en general. A continuación, trataremos las creencias religiosas bajo dos puntos de vistas totalmente opuestos: por un lado, se expondrá la posición de autores que dicen que las creencias religiosas sí tienen una evidencia razonable que las sustenta y, por otro, nos encontraremos con autores que afirman que dichas creencias no pueden ser justificadas racionalmente porque lo espiritual refiere el ámbito de lo indecible, en el cual no es factible afirmar que los enunciados religiosos son apropiados a ser verdaderos o falsos.

Palabras claves: creencia; religión; fe; evidencia racional; falsación; Flew
\end{abstract}

Pontificia Universidad Javeriana, Bogotá, Colombia.

Correo electrónico: castaneda.f@javeriana.edu.co

Para citar este artículo: CASTAÑeda VARgas S.J., F.H. (2016). En búsqueda de una evidencia razonable de las creencias religiosas. Universitas Philosophica, 33(66), pp. 129-150. ISSN 0120-5323, ISSN en línea: 2346-2426, doi:10.11144/Javeriana.uph33-66.berc 


\title{
IN SEARCH OF EVIDENCE FOR THE RATIONALITY OF RELIGIOUS BELIEFS
}

\author{
Fredy Humberto Castañeda Vargas, S.J.
}

\begin{abstract}
This article inquires whether or not religious beliefs are rational, that is to say, whether or not they can be rationally sustained. The point of the article is not to prove the existence of God, but rather simply to show whether or not religious language has real meaning. To do this, we shall examine the concept of belief in general. Then we shall look at religious beliefs in particular from two opposing points of view: on the one hand, from the position of authors who claim that religious beliefs can in fact be sustained by rational evidence, and on the other hand, from the perspective of other authors who affirm that these beliefs cannot be rationally justified, because spiritual discourse refers to the ineffable, which deprives it of the means to verify or deny its propositions.
\end{abstract}

Key words: belief; religion; faith; rational evidence; falsation; Flew 
UNO DE LOS PRINCIPALES PROBLEMAS que debe abordar la filosofía de la religión es la relación entre fe y razón, de donde surgen las siguientes preguntas: ¿es la creencia religiosa racional? o ¿la fe es esencialmente irracional? Si podemos surtir las demandas de la creencia religiosa, ¿es posible creer razonablemente estas demandas? Aunque no tengamos una prueba deductiva de la existencia de Dios, ¿es razonable creer que Dios exista? En este debate entre razón y fe han subsistido dos posiciones contrarias. La primera enuncia que la fe y la razón son conmensurables, es decir, sí es razonable creer en Dios; la segunda se opone a la anterior aserción: no es razonable creer en Dios. La mayoría de los adeptos a la primera posición, que siguen a Tomás de Aquino, dan poca importancia a la compatibilidad entre los 'preámbulos de la fe' (referidos, por ejemplo, a la existencia de Dios y a su naturaleza) y los dogmas de la fe (referidos, por ejemplo, a la doctrina de la encarnación). Pocos han logrado mantener una armonía entre fe y razón, como es el caso de Kant, que dice que la creencia religiosa debe darse exclusivamente dentro de los límites de la razón.

A su vez, la segunda posición se fracciona en dos posturas. Unos dicen que la fe está opuesta a la razón y pertenece a lo irracional, como es el caso del danés Søren Kierkegaard, que sostiene que no podemos tener un conocimiento de Dios, pues la única vía para relacionarnos con lo divino es la fe. La segunda postura afirma que la fe está por encima de la razón, es decir, es transracional. La siguiente tabla realizada por David Steward (1998, p. 94) nos ilustra las diferentes actitudes posibles entre la relación fe y razón. La razón exige que nosotros conozcamos con una certeza demostrable o con una fuerte evidencia; la fe, en cambio, demanda que creamos sin la necesidad de una prueba o evidencia.

\begin{tabular}{ccl}
\hline FE & RAZÓN & \\
\hline Sí & Sí & Tomás de Aquino \\
\hline No & No & Anthony Flew \\
\hline Sí & No & Søren Kierkegaard \\
\hline No & Sí & Voltaire (deísmo) \\
\hline
\end{tabular}

Con relación a estas formulaciones, Tomás de Aquino tiene la posición más optimista al afirmar que tenemos un conocimiento de Dios y que, a la vez, la fe es defendible. Por el contrario, Anthony Flew enuncia que no podemos tener un conocimiento de Dios y que, además, nuestras demandas de la fe son indefendibles. $\mathrm{Si}$ aceptamos que no es posible tener una prueba contundentemente racional, 
podremos entonces abarcar la vía propuesta por los pragmatistas, en particular William James, que dice que podemos y debemos actuar por principios en los que no tenemos una certeza y una evidencia.

De este modo, este artículo tiene la intención de buscar la evidencia razonable acerca del tema de las creencias religiosas. Para esto, en un primer momento, investigaremos la naturaleza de la creencia en general, a partir de ello analizaremos los postulados principales de la creencia religiosa desde las siguientes tres concepciones: como acto mental, como disposición y como estado disposicional adquirido.

Luego de ver las características de la creencia en general, nos preguntaremos, como el principal problema planteado en este trabajo, si son o no razonables las creencias religiosas. Este interrogante no pretende abarcar el problema de la existencia o no de Dios, sino indicar si el lenguaje religioso tiene o no significado o sentido. Para este propósito, se mostrará cuál es la distinción entre la creencia en general y la creencia religiosa en particular. Posteriormente, presentaremos dos tendencias opuestas que intentan responder la siguiente pregunta: ¿son razonables las creencias religiosas? Por último, y con base en estas dos tendencias esbozaremos "la prueba del ateísmo" planteada por Anthony Flew, por medio de la que pretende que los teístas presenten pruebas o evidencias fehacientes que tumben al ateísmo, especialmente al que se refiere a aquellos que no son teístas.

\section{Las creencias en general}

ANTES DE INICIAR NUESTRO TRABAJO, que pretende preguntarse por el posible significado de las creencias religiosas, es decir, si estas pueden ser o no razonables, es conveniente detallar cómo algunos autores contemporáneos de la Universidad de Oxford miran las creencias en general. De este modo, en esta sección abordaremos los postulados de la creencia en general para determinar si esta puede ser o no considerada apropiada a la verdad.

De esta forma, es importante afirmar que aunque las creencias tienen una validez subjetiva y no objetiva, esto no implica que estas no tengan un carácter público, es decir, la creencia es el aspecto que cualquier individuo puede compartir o comparar, ya que nuestros comportamientos son manifestaciones externas de lo que creemos privadamente. Sin embargo, es importante anotar que no debemos confundir las creencias con los comportamientos adheridos a ellos. Así, si 
una persona cree en un determinado acontecimiento, este puede ser común a un cierto número de individuos que originan un conjunto de respuestas comunes.

Una vez hecha esta aclaración, podemos afirmar que las creencias pueden ser abordadas desde tres concepciones. La primera es la creencia como acto u ocurrencia mental, que tiene una cualidad especial; la segunda es verla como una disposición, y la tercera consiste en la creencia como una disposición adquirida. La metodología de esta sección enunciará el contenido de cada concepción con sus respectivos autores, y luego se postularán sus dificultades. Pasaremos de una concepción a otra cuando al encontrar falencias de una, debamos continuar con la siguiente. Así, de la primera seguiremos a la segunda, y de esta a la tercera.

\subsection{LA CREENCIA COMO ACTO U OCURRENCIA MENTAL}

LA CONCEPCIÓN DEL CREER en cuanto acto mental de una cualidad especial fue asumida por autores como Descartes, Hume y Locke. "Para Descartes, la creencia es un acto de voluntad, para Hume un sentimiento peculiar, para Locke un acto de asentimiento" (Villoro, 1982, p. 25). Por otra parte, tanto en la línea fenomenológica de Husserl como en la de James-Russell, se consideró que la creencia es una ocurrencia mental. Husserl nombró la creencia como una cualidad de un acto denominada "posición"; y Russell la comprendió como una actitud proposicional subjetiva. Pero todos estos autores tienen una definición de la creencia en sentido mentalista, pues para ellos "creer es un sentimiento o un acto de una cualidad específica que ocurre en la mente de un sujeto" (Villoro, 1982, p. 27); por tanto, solo en la conciencia o en la mente del sujeto es accesible tal ocurrencia.

Sin embargo, esta primera concepción de las creencias como acto u ocurrencia mental tiene algunas dificultades: primero, no todas las creencias son ocurrencias mentales, ya que yo puedo poseer una creencia sin que necesariamente la tenga presente en la conciencia, por ejemplo, mientras estoy leyendo un libro creo en una gran cantidad de cosas, como que el sol es una estrella, que mi hermana es temerosa o que el fuego quema, pero ninguna de ellas concurre de manera presente a mi mente. De esta manera, creer se parece más a 'poseer' que a 'tener', según la distinción que hace Platón en el Teeteto: tengo algo que está presente ahí; poseo gran cantidad de cosas que no tengo en un momento determinado (Tee. 197bc). Por tanto, la creencia no es realizar un acto especial, sino poder realizar muchos actos en diversas circunstancias. Por tal motivo, Gilbert Ryle en su 
libro El concepto de lo mental, sostiene que creer es una tendencia a ejecutar algo, pero no obligatoriamente debe hacerlo actual ${ }^{1}$. Creer que el fuego tiene ciertas características, implica que uno se comporte de un modo adecuado frente a una hoguera, poder diferenciar una llama de una pintura, poder utilizar el término fuego en distintas circunstancias; sin embargo, esto no indica tener presente un algo en la mente. Dentro de los autores mencionados en esta primera concepción de la creencia, Husserl es el único que afirmaba que la posición de la creencia podía ser latente, como en el caso de creer que el suelo que pisamos no se va hundir, sin que la tenga presente en este momento. Gracias a esta latencia nos podemos mover en el mundo. Pero esas creencias no son actos ni ocurrencias de la conciencia, sino una disposición consciente o inconsciente.

Segundo, si la creencia fuera una cualidad especial de la conciencia nadie podría acceder a la conciencia del otro para saber su creencia; así, por ejemplo, si una persona dijera que no tiene un sentimiento de seguridad, ni ejecuta un acto de asentimiento, ni de "posición" alguno cuando cree que está obligada a aceptar lo que dice, pues no se podría comprobar lo contrario.

Tercero, la creencia no puede ser un sentimiento de convicción o de seguridad, aunque las voliciones y los sentimientos sean condiciones para que se dé una creencia. De esta manera, las creencias religiosas, políticas o morales suelen estar acompañadas de sentimiento de firmeza o de seguridad; las creencias científicas no necesariamente lo están. Para creer que un triángulo está compuesto de dos ángulos rectos no existe, generalmente, ningún sentimiento adjunto. Otro ejemplo ilustrativo se da cuando un niño tiene miedo de reprobar un examen porque no ha estudiado; sin embargo, él cree en la mayoría de sus respuestas, pero no tiene ningún sentimiento de firmeza o de seguridad. Entonces, ni el sentimiento de firmeza ni los actos de voluntad son condiciones necesarias de una creencia, tal como lo afirmaba David Hume.

1 Para Ryle, conocer y creer son verbos disposicionales de tipos completamente diferentes. "'Conocer' es un verbo de capacidad, y pertenece a la clase de los verbos de capacidad que son usados para significar que la persona descrita puede hacer ciertas cosas, o hacer que ellas salgan bien. 'Creer', en cambio, es un verbo de tendencia; un verbo que connota que se ha hecho algo, o que se lo ha hecho andar bien. El sustantivo 'creencia' puede ser calificado por adjetivos tales como 'obstinada', 'vacilante', 'firme', 'invencible', 'estúpida', 'fanática', 'sincera', 'intermitente', 'apasionada' y 'pueril', algunos de los cuales son apropiados también para sustantivos tales como 'confianza, 'deslealtad, 'inclinación', 'aversión', 'esperanza', 'hábito', 'celo’ y 'adicción”' (Ryle, 1967, p. 119). 
Por tanto, las creencias no pueden ser solo actos mentales privados o internos de la conciencia a los que otras personas no pueden acceder, debido a que no se podría mencionar la creencia con unas características mínimas de objetividad o validez. Por esta razón, se hace necesario abordar la segunda concepción.

\subsection{LA SEGUNDA CONCEPCIÓN DE LA CREENCIA COMO UNA DISPOSICIÓN}

R. B. BRAITHWAITE FUE EL PRIMERO en postular esta concepción en el contexto de la Universidad de Oxford, en la que distintos profesores (Price, Prichard, Malcom y Griffihts) investigaban la naturaleza de la creencia a través de un análisis del lenguaje proposicional. Desde esta perspectiva podemos afirmar que las creencias se describen por medio de proposiciones condicionales. Pero ¿qué significa esto? Según Braithwaite, las creencias son disposiciones que se formulan hipotéticamente de la siguiente forma: $\mathrm{si} \mathrm{P}$ tiene una disposición $d$, implicará que si P está en una circunstancia $c_{l}$, tendrá un comportamiento como $x_{1}$; si P está en la circunstancia $c_{2}$, se comportará como $x_{2}$. Pero no existe ninguna propiedad de $\mathrm{P}$ que sea observable aparte de las diversas circunstancias $c_{1}, c_{2}$, etc., $\mathrm{y}$ de los comportamientos $x_{P}, x_{2}$, etc. (Braithwaite, 1975, p. 51). De esta forma, se puede enunciar que una disposición no es una ocurrencia mental, ya que estas son directamente observables en los objetos; por el contrario, las creencias son características que se deben atribuir a los objetos con el fin de que se puedan explicar algunas ocurrencias, es decir, las creencias no son un compuesto de acciones reales, sino un compuesto de disposiciones a la acción, propensiones que se convertirán en acciones en circunstancias pertinentes. Un ejemplo ilustrativo es el siguiente: un vidrio sujeto a unas determinadas circunstancias de presión o de choque se quebrará. Para explicar este fenómeno debemos suponer que el vidrio tiene la propiedad de la fragilidad, pero tal característica no es un comportamiento que observemos directamente.

Con todo, es necesario aclarar que hay algunas creencias que no necesariamente se convertirán en comportamientos. Así, con lo anterior no se está afirmando que una creencia forzosamente debe traducirse en una acción, sino que si únicamente se dan unas determinadas circunstancias, una persona se comportará de una manera en la que se presume que existirá una disposición a actuar llamada creencia. Sin embargo, si no se puede actualizar tal disposición, no se sigue que se deje de estar dispuesto a obrar de la misma manera. De esta forma, existen 
creencias que nunca hemos tenido la oportunidad de traducirlas en comportamientos, pero si la ocasión se diera, tendríamos tal disposición.

Por tanto, las ventajas que tiene la concepción de la creencia como disposición con respecto a la creencia como ocurrencia mental son las siguientes: primero, explica que no toda creencia es una ocurrencia que únicamente se presenta en un determinado lapso de tiempo, sino que también existen creencias inconscientes, latentes y potenciales. Segundo, las creencias pueden ser comprobables objetivamente, porque no se necesita de un análisis introspectivo para establecer las creencias de otra persona, sino que estas se inducen de comportamientos observables en sí mismo o en otra persona. Tercero, no es necesario hacer una descripción en términos de seguridad o de viveza como lo hace Hume. Basta con expresarlo mediante proposiciones condicionales más exactas, que no impliquen la descripción directa de un objeto dado, sino que describan un término teórico referente a un estado que se debe suponer en la persona para explicar ciertos hechos observables; pero que no es indispensable observar directamente. Y cuarto, estas concepciones no solo permiten explicar las creencias como ocurrencia mental en que el sujeto confiesa conscientemente, sino que también es posible dar razón de creencias reales no confesadas de dicho sujeto, pues una persona puede demostrar que cree más con sus comportamientos que no expresa a los demás.

No obstante, en esta concepción de la creencia también encontramos dificultades, porque si se interpreta la creencia como un estado incognoscible del sujeto, que es indispensable suponer para que, dados unos antecedentes, se logre un determinado número de respuestas, dicha concepción podría valer para cualquier comportamiento instintivo. Así, al comportamiento de la abeja cuando construye sus celdas, se le tendría que llamar también una creencia. Además, ¿cómo se podría distinguir la creencia de otra clase de deseos, emociones o intenciones que hacen que el sujeto tenga un cierto número de comportamientos? Para responder este cuestionamiento es necesario seguir con otra vía más adecuada para definir la creencia.

\subsection{LA CREENCIA COMO DISPOSICIÓN ADQUIRIDA}

Es INDISPENSABLE ACLARAR que las creencias no son, en general, solamente un conjunto de estímulos y respuestas, sino también un estado disposicional adquirido que se distingue de las disposiciones instintivas o genéticas. Esto 
significa que en algún momento de nuestras vidas las creencias fueron aprehendidas por medio de la percepción, de la memoria o del entendimiento, sin que necesariamente se encuentren presentes en la conciencia, esto es, pueden ser inconscientes o latentes. Como decía Wittgenstein (2000): "el niño aprende a creer en el adulto. La duda viene después de la creencia. Aprendía una gran cantidad de cosas y las acepté con base a la autoridad humana. Después he descubierto que se veían confirmadas o refutadas por mi propia experiencia” (p. 162, No. 160-161).

Retomando un nuevo intento de concepción de creencia, podemos enunciar que estas son apropiadas a la verdad, ya que, por un lado, la creencia debe remitir al saber, y viceversa, pues al fin y al cabo ambos aspectos se refieren a un mundo real y objetivo; por otro lado, si una persona cree en un cierto suceso, este puede ser creído y compartido por un grupo de individuos, por lo que las creencias deben ser comprendidas en función de aseveraciones y no en función de imperativos o de interrogantes. Así, es posible afirmar que una creencia cualquiera es el producto de una evidencia, cuyo interés es epistémico.

De esta manera, se pueden sintetizar tres condiciones en las que se da la creencia: $S$ cree que $p$ si y solo si:

(1) S está en un estado adquirido $x$ de disposición a responder de determinada manera ante variadas circunstancias;

(2) $p$ ha sido aprehendida por $S$;

(3) $p$ determina $x$.

De donde podríamos proponer la siguiente definición de creencia: un estado disposicional adquirido, que causa un conjunto coherente de respuestas y que está determinado por un objeto o situación objetiva aprehendidos. (Villoro, 1982, p. 71)

La primera condición se refiere a que la creencia es una disposición individual, es decir, la creencia es un estado interno del sujeto, sin la cual no se podría entender la consistencia de sus respuestas. Aquí es oportuno introducir, en una primera instancia, la concepción de creencia en Kant:

El tener por verdad, o validez subjetiva del juicio, en relación con la convicción (que posee, al mismo tiempo, validez objetiva), tiene los tres grados siguientes: opinión, creencia y saber. La opinión es un tener por verdad con 
conciencia de que es insuficiente tanto subjetiva como objetivamente. Si sólo es subjetivamente suficiente y es, a la vez considerado como objetivamente insuficiente, se llama creencia. Finalmente, cuando el tener por verdad es suficiente tanto subjetiva como objetivamente, recibe el nombre de saber. (Kant, 2006, p. 640. A 822 B 850)

Por lo anterior, la creencia no es concebible solamente por el conjunto de estímulos-respuestas, sino que es preciso aclarar que al ser adquirida, difiere de ser disposiciones genéticas o instintivas. La segunda condición significa que el objeto al cual una persona se dirige, debe ser aprehendido por aquél en un determinado momento por medio de la percepción, la memoria o el entendimiento, sin que necesariamente esté siempre presente en la conciencia. Además, esta condición une a $p$ y al objeto haciendo que la creencia pueda ser real para cualquier otro sujeto. La tercera condición indica que la creencia se distingue de los demás estados disposicionales en la manera en que determina o delimita la forma como $S$ se dispone a responder, según la condición 1 .

Una vez caracterizadas las creencias en general, podemos abordar las creencias religiosas y buscar su evidencia razonable.

\section{La evidencia razonable de las creencias religiosas}

CON EL FIN DE BUSCAR ALGUNA EVIDENCIA racional de las creencias religiosas, haremos el siguiente itinerario: en primer lugar trataremos la diferencia entre las creencias en general y las creencias religiosas, en específico; después abordaremos las dos tendencias opuestas que intentan contestar la pregunta: ¿son las creencias religiosas razonables o no?; y, por último, plantearemos el desafío de Anthony Flew con su prueba de la "presunción del ateísmo". Dicha prueba servirá de base para responder si es posible afirmar o negar que las creencias religiosas son o no razonables.

2.1 LA DIFERENCIA ENTRE LAS CREENCIAS EN GENERAL Y LAS CREENCIAS RELIGIOSAS EN PARTICULAR

COMO VIMOS EN LA SECCIÓN ANTERIOR, si caracterizamos a las creencias en general como estados disposicionales adquiridos desde nuestra infancia y, por tanto, que pueden tener un carácter público, también podremos aseverar que las 
creencias religiosas pueden ser públicas, ya que una gran cantidad de personas comparten un mismo credo o tienen una misma religión como historia. No obstante, las creencias religiosas se distinguen de las creencias en general en que no queda claro afirmar que sean apropiadas a la verdad, es decir, las creencias religiosas no pueden ser tratadas como aseveraciones de las que se pueda decir que son verdaderas o falsas. De esta manera se tratará la cuestión de que si las creencias religiosas pueden o no ser justificadas con una evidencia racional suficiente.

De lo anterior podemos deducir que la forma como se diferencian las creencias en general de las creencias religiosas se da por una supuesta falta de evidencia suficiente por parte de estas, que hace que una persona razonable se pregunte por tal evidencia. Además, otra diferencia radica en que las expresiones religiosas involucran la fe, cuya sustentación conlleva un aspecto intensamente emocional que involucra más el corazón que la razón. Así, para Kierkegaard, por ejemplo, la "fe es la más valiosa virtud porque precisamente ésta es objetivamente incierta" (Pojman, 2003, 337), es decir, la fe es la inspiración de los más profundos anhelos y esperanzas, en la que la razón es incapaz de develar ${ }^{2}$. De igual modo, para Lonergan, la fe es un conocimiento nacido del amor religioso, donde Dios llama y su pueblo responde a tal amor a largo de su historia, es decir, el hombre responde con un conocimiento de amor ante la vocación de Dios a su pueblo, en el que aquél se pregunta: "¿lo amaré para corresponderle, o lo rechazaré? ¿Viviré fuera del don de su amor, lo retendré o lo desecharé?” (Lonergan, 1994, p. 117); y solo después se formulará interrogantes como la existencia o naturaleza de Dios, que muestran al fin y al cabo, la exigencia del creyente por conocerlo y del no creyente para darse razones de no hacerlo.

Como podemos ver, al estar de por medio la fe en las creencias religiosas, no resulta fácil buscar en ellas una evidencia suficiente que las sustente. Por ello, vale la pena preguntar: ¿son las creencias religiosas razonables?; en otras palabras, ¿las creencias religiosas pueden ser sustentadas bajo una evidencia suficiente?

2 La fe es la condición para entender la verdad, la condición que Clímaco tiene, en orden de distinguir su hipótesis de la posición socrática, la fe debe ser asumida como algo que carece el ser humano y, por tal motivo, debe recibir de Dios como un don o un regalo en que se espera que cada hombre, a nivel individual, responda por medio de una relación íntima con su creador en el que no necesita de medios racionales (Evans, 2002, p. 93). Por tal razón, la fe es un don divino e individual, al que el hombre responde. 
¿Podemos abarcar las expresiones religiosas como aseveraciones o afirmaciones, que puedan ser apropiadas o no a la verdad? Estos interrogantes no aluden a comprobar o no la existencia de Dios, sino simplemente a saber si el lenguaje religioso como tal tiene o no sentido.

\subsection{LAS DOS TENDENCIAS OPUESTAS QUE INTENTAN CONTESTAR LA PRE-} GUNTA: ¿SON LAS CREENCIAS RELIGIOSAS RAZONABLES O NO?

LA PRIMERA TENDENCIA ENFOCA la mirada del problema de la evidencia racional bajo el lenguaje religioso analítico heredado por los positivistas radicales de Viena, que afirmaban que las expresiones religiosas carecen de sentido al no estar dentro del conjunto de los enunciados matemáticos y tautológicos, ni dentro de los enunciados fácticos (los científicos); es decir, los enunciados religiosos no hacen parte de aquellos que se pueden calificar como verdaderos o falsos gracias a la corroboración con los hechos. Ante este punto de vista tan radical reacciona en contra Karl Popper con su teoría del falsacionismo. Este nuevo criterio afirma lo siguiente: "no exigiré que un sistema científico pueda ser seleccionado, de una vez para siempre, en un sentido positivo; pero sí que sea susceptible de selección en un sentido negativo por medio de contrastes o pruebas empíricas" (Popper, 2004, p. 40). Así, en su teoría de la demarcación, que delimita la ciencia de la metafísica y de la religión, esta ya no es vista como un conjunto de enunciados carentes de sentido, sino de aseveraciones imposibles de ser falseadas en principio.

Precisamente, esta doctrina del falsacionismo es aprovechada por Antony Flew, quien la aplica a las expresiones religiosas con el fin de buscar una evidencia racional suficiente que tumbe lo que él denomina la "presunción del ateísmo".

De esta forma, tanto W. Clifford como A. Flew están interesados en encontrar una evidencia que fundamente a las creencias religiosas. Flew, por un lado, sustenta lo que él ha denominado "la presunción del ateísmo". Por ejemplo, en las cortes judiciales se defiende la presunta inocencia hasta que establezca una evidencia que tumbe dicha presunción. Esto implica, igualmente, que para aquellos que crean que 'Dios existe' debe exigírseles presentar una evidencia que derroque al ateísmo y, si esto sucede, entonces tendremos buenos fundamentos para creer en verdad en la aseveración 'Dios existe'. Según Flew, hasta que dichos fundamentos no se produzcan, no tendremos razones para creer y, por tal motivo, la única postura razonable sería el ateísmo negativo, cuyos representantes sostienen 
no ser teístas o que Dios les parece indiferente para sus vidas. Por otro lado, para Clifford, la defensa de la opinión de que las creencias en general no son una cuestión privada, debido a que nuestras vidas, palabras, frases, procesos y modos de pensamiento son propiedad común, nos llevará a buscar una evidencia suficiente cuando creamos ya sea en algo o ya sea en que Dios existe.

Ahora, la otra tendencia importante, cuya característica principal afirma que no necesitamos de ninguna evidencia racional que sustente las creencias religiosas, está enunciada, a su vez, por dos posiciones: los pragmatistas (William James) y los fideístas (Kierkeegard, Wittgenstein y sus seguidores).

Así, William James, como pragmatista, critica la propuesta de Clifford, ya que de muchas situaciones de la vida no podemos esperar la probabilidad de una evidencia suficiente, como se presenta en las cuestiones morales, debido a que a si consideráramos una prueba racional para lo moral, esto no nos mostrará qué actitud es correcta o incorrecta. Asimismo, con respecto a las expresiones religiosas en tanto opciones vivas, importantes y forzadas, no esperamos encontrar una evidencia suficiente, ya que el escéptico, que prefiere evitar el error en vez de arriesgarse a tener una opción, será un irracional, puesto que si la religión llega a resultar falsa, evitaremos el error, pero si es verdadera perderemos lo bueno de ella ${ }^{3}$.

Sin embargo, las personas que están de acuerdo con Clifford afirman que el investigador no se deja afrontar con las opciones descritas por James, ya que cuando no podemos acceder a la evidencia ni al argumento, tampoco podemos hacerlo con la creencia, por lo menos la creencia responsable. Así, puede haber deseos, esperanzas u otros estados, sin necesidad de evidencia, pero no es permitido

3 Opción se refiere a la decisión entre dos hipótesis; así, existen tres clases de opciones: por un lado, una opción viva será la elección entre dos hipótesis vivas, por ejemplo, ser un ateo o un creyente, pues este dilema influirá de manera más fuerte en las creencias, que si escogiéramos entre ser mahometano o neo-platónico; por otro lado, una opción forzada se da cuando debemos elegir obligatoriamente una u otra hipótesis, por ejemplo, o aceptas esta verdad o tienes que apartarte de la comunidad que cree en ella. Como vemos, aquí hay una disyunción lógica que nos impide optar por otra alternativa. Por último, tenemos las opciones trascendentales que nos hablan de la distinción entre dos oportunidades, escoger una de ellas implica algo muy importante; tal es el caso de elegir entre ir a la luna este verano o permanecer en el país de origen, ya que esto significa que posiblemente será la única oportunidad que se presente de ir a la luna, y además, que si se elige ir a la luna no habrá chance de retractarse. En cambio, una opción trivial implica que la opción sea reversible y que se pueda volver a presentar una nueva ocasión en la cual la opción se vuelve a dar; por ejemplo, este verano tengo la opción de ir a Europa o a Estados unidos (James, s.f., pp. 7-109). 
pensar lo mismo de las creencias. Por tal razón, debemos estar pendientes tanto de tales opciones como de las creencias teniendo en cuenta su evidencia.

Por otro lado, nos encontramos con la postura fideísta. Esta afirma que la razón objetiva es inadecuada para la creencia religiosa, pues la fe no se justifica mediante la razón. La fe genera su propia justificación o su propio criterio interno de valoración. Aquí expondremos el punto de vista fideísta wittgensteiniano que enuncia que la religión es una actividad en la cual la razón es inoperante.

Para comprender la postura fideísta de Wittgenstein, es conveniente analizar el texto "Lecciones sobre creencia religiosa". En este texto, Wittgenstein afirma que la creencia religiosa está en un nivel o estrato diferente a las creencias y al lenguaje de la vida común y corriente. La creencia religiosa no se deja remover tan fácilmente, ya que tiene imágenes distintas, y no se deja contradecir o no contradecir, ya que, aunque utilice palabras comunes y conocidas, no se sabe si se le comprende o no. La técnica corriente del uso de las palabras no funciona con ella: "Estas controversias parecen completamente diferentes de cualquier controversia normal. Las razones parecen enteramente diferentes de las razones normales. En cierto sentido no son nada concluyentes" (Wittgenstein, 1992, p. 132); y puesto que las creencias religiosas no se pueden comparar, podemos señalar que Wittgenstein no considera las creencias como estados mentales o procesos psíquicos temporales o momentáneos, como cuando uno tiene un dolor de muela.

Por tal razón, la evidencia o prueba racional no tiene ningún sentido para la religión. En el lenguaje religioso se usan expresiones como: "creo que sucederá tal y tal cosa, pero no las usamos del mismo modo que las usamos en la ciencia" (Wittgenstein, 1992, p. 133), y, aunque el cristianismo esté sustentado en hechos históricos, estos no tienen el mismo significado que tiene los hechos históricos de las creencias ordinarias. Así, las personas creyentes no emplean la duda de la misma manera que la emplearía ante una proposición histórica. Con todo lo anterior, podemos indicar que la creencia religiosa no es racional ni tiene la intención de serlo, ya que si el señor Lewy es religioso y dice que cree en el día final, yo no sabría siquiera decir si le entiendo o no; pues si alguien dijera que la creencia religiosa razona cometiendo errores, no podríamos saber cómo cometen tales errores, puesto que solo se habla de error en un determinado sistema o 
un determinado juego y no en otro ${ }^{4}$. Por tal razón, la evidencia o prueba racional no tiene ningún sentido para la religión. En el lenguaje religioso se usan expresiones como: "creo que sucederá tal y tal cosa", pero no las usamos del mismo modo que las usamos en la ciencia.

Según lo anterior, las creencias religiosas son expresiones que no tienen nada que ver con lo científico. Una cosa es la ciencia y otra muy distinta es la religión. Esta, al tener su propia racionalidad, prescinde de cualquier hipótesis, de cualquier evidencia que cuente en contra de ella, de cualquier fundamento empírico que la sustente; por tal motivo, no podríamos considerar al creyente como irracional. De este modo, para Wittgenstein, el creyente es aquel que al desfigurar el lenguaje, hace que no se sepa si le entiende o no, o si podemos estar de acuerdo con sus apreciaciones o no. Por tal motivo, es imposible refutarlo. De ahí que para comprender el lenguaje religioso deberíamos tener las mismas imágenes (pictures) del creyente o usar estas imágenes como él lo hace.

No obstante, se pueden encontrar varias falencias en la postura de Wittgenstein. En muchos sistemas religiosos sí es posible relacionar la ciencia con la religión. En ellos se expresan las creencias por medio de un lenguaje discursivo. Si no fuera así, las metáforas religiosas serían simplemente enunciados sin sentido. Además, hasta las religiones más primitivas contienen cosmologías. Por otra parte, no podemos afirmar que las creencias religiosas desfiguran el lenguaje, pues el creyente, sin tener en cuenta sus imágenes, pretende expresar sus experiencias bajo proposiciones que supuestamente contienen verdades.

\subsection{EL DESAFío DE ANTHONY FLEW}

De LO ANTERIOR PODEMOS INFERIR que la religión no puede librarse del dictamen de la razón, pues la fe es la etapa que le sigue a esta; es más como un poner

4 "En la práctica del uso del lenguaje una parte grita las palabras, la otra actúa de acuerdo con ellas; en la instrucción en el lenguaje se encontrará este proceso: el aprendiz nombra los objetos. Esto es pronuncia la palabra cuando el instructor señala la piedra $-Y$ se encontrará aquí un ejercicio más simple: el alumno repite las palabras que el maestro le dice -ambos procesos se asemejan al lenguaje. Podemos imaginarnos también que todo el proceso del uso de palabras en (2) es uno de esos juegos por medio de los cuales aprenden los niños su lengua materna. Llamaré a estos juegos juegos del lenguaje. [...] Llamaré también "juego de lenguaje" al todo formado por el lenguaje y las acciones con las que está entretejido" (Wittgenstein, 1988, p. 25, \$7). "El significado de una palabra es su uso en el lenguaje" (Wittgenstein, 1988, p. 61, §43). 
lo que a esta le falta, que como algo independiente de ella; o, como afirma Anthony Kenny: "La fe es por definición una creencia en algo por una razón particular: la postura del desafío de Flew tiene su razón de ser" (Romerales, 1992, p. 43). En tal desafío. Flew concluye, bajo lo que él denomina la muerte de las mil cualificaciones, que algo que al principio parece ser una aserción o una afirmación, luego de un ataque severo que pretende refutarla, los que intentan defenderla terminan tras de un conjunto de estrategias no afirmando nada. De esta forma, si la aserción original que afirmaba que "hay un jardinero cuidando el jardín" no deja ser refutada, esta fallece con la muerte de las mil cualificaciones:

$\mathrm{Al}$ respecto Flew (1992) sostiene:

Érase una vez dos exploradores que dieron con una claro de jungla. En el claro crecían muchas flores y muchas malas hierbas. Un explorador dice: "Algún jardinero debe de cuidar el terreno". El otro no está de acuerdo. "No hay ningún jardinero". Así que montan sus tiendas y montan guardia. Ningún jardinero es visto jamás. "Pero quizá sea un jardinero invisible". Así que erigen una barrera alambrada de púas. La electrifican. Patrullan con sabuesos [...] Pero ningún chillido sugiere jamás que algún intruso haya recibido una descarga. Ningún movimiento del alambre delata jamás un trepador invisible. Los sabuesos nunca ladran. Sin embargo, el creyente aún no está convencido. "Pero hay un jardinero, invisible, intangible, insensible a las descargas eléctricas, un jardinero que no tiene olor y no hace ruido, un jardinero que viene secretamente a cuidar el jardín que ama". Al final el escéptico se desespera: "Pero ¿qué queda de tu aserción original? Lo que tú llamas un jardinero invisible, intangible, eternamente elusivo, ¿en qué demonios difiere de un jardinero imaginario o incluso de ningún jardinero en absoluto? (Flew, 1992, pp. 47-48).

De este modo, aseveraciones como "Dios nos ama", "Dios es el creador del mundo", "Dios nos ama como un padre a sus hijos", resultan no falseables, debido a que el creyente no permitirá que nada cuente en contra de sus aseveraciones. Así, Flew lanza una pregunta desafiante: “¿qué tendría que ocurrir o haber ocurrido que constituya para Ud. una refutación del amor, o de la existencia de Dios?" (Flew, 1992, p. 51). Ante tal desafío se generan dos posturas: "el ala derecha de Oxford" y "el ala izquierda de Oxford".

Representantes del ala izquierda como Hare, Braithwaite, Hepburn y MacIntyre coinciden con Flew en afirmar que los asertos religiosos no tienen 
contenido empírico y, por ende, cualquier visión que tengamos del mundo no nos darían alguna información. Por tal motivo, ellos consideran a la religión como un acontecimiento no racional, con lo que se cierra cualquier acceso a reactivar las pruebas clásicas de la existencia de Dios y, como diría James, cualquier opción religiosa no tendría motivos racionales, sino simplemente motivos emotivos o pasionales. Esta corriente sostiene, además, que las afirmaciones religiosas tienen que ver sobre todo con sentimientos, con actitudes frente al mundo y con la expresión de una conducta o modo determinado de vida, cuya historia, como afirma Braithwaite, serviría para incentivar tal modo o conducta de vida.

Contrario a esta perspectiva, los representantes del "ala derecha": Mitchell, Hick, Crombie y Ryle, enuncian que las aseveraciones religiosas al tener contenido (empírico) son falseables, con lo que estarían del mismo lado de Flew, pues no renuncian a buscar una prueba racional fehaciente de las expresiones religiosas. Dentro las distintas posturas de esta ala nos encontramos con la Mitchell, que afirma que el creyente sí tiene en cuenta que ciertos hechos como el mal en el mundo pueden contar en contra de sus creencias; sin embargo, no por ello este dejará que tales hechos cuenten decisiva y conclusivamente en contra de sus expresiones religiosas.

Asimismo, Hick, Crombie y Ryle coinciden en enunciar que aunque las experiencias religiosas sean parciales, el creyente anticipa el horizonte de sentido total de la vida, que le posibilita dar un significado a su creencia. Así, Hick nos habla, por un lado, que la presencia de Jesucristo es el camino para conocer al $\mathrm{Pa}$ dre y, por otro, que por medio de la verificación escatológica se podría, aunque no en el momento, falsear el contenido del lenguaje religioso y, de esta forma, saber quién tendría la razón: el creyente o el no creyente. Pero esta posibilidad queda abierta en el tiempo. De este modo, el creyente tendría expresiones factibles de verificarse; él está haciendo, por ahora, una opción real que no es vacía. Crombie, por su parte, nos dirá que para completar el cuadro necesitamos tener en cuenta la vida del más allá. De igual modo, Gilbert Ryle enuncia que muchas cosas en la vida no están dentro de esta.

Ahora bien, pasando a las falencias de las dos alas, Flew critica a Hare, por un lado, porque el término blik (actitud) considera las creencias simplemente como actitudes, con lo que estas no podrían abordarse como aserciones y, si esto ocurre, muchas de las actividades de los creyentes pasarían por tontas o por falsas. Además, 
Hare no da la posibilidad de distinguir cuándo una creencia religiosa es justa y cuando es errónea y, de este modo, no se puede defender el blik que uno tenga.

Por otro lado, la estructura de la religión difiere por tener en cuenta la fe, que no se da, por supuesto, aisladamente, sino en comunidad, y cuya sustentación se presenta a lo largo de la historia. También podemos comparar esta postura con la de Kierkeergard, que opina que aunque el cristiano tuviera un conocimiento evidente de los sucesos históricos de la vida, pasión y muerte de Jesucristo, esto no influiría en nada en su relación de confianza con Él. Con respecto a esto, Lonergan sí considera como cierta la relación de Dios con su pueblo, con el que se comunica a través de la historia. Desde este punto podemos criticar la postura de MacIntyre que solo considera la autoridad de Jesucristo sin tener en cuenta la historia. Si el único criterio fuera la autoridad de Jesucristo, entonces ¿qué quedaría de las demás religiones?, ¿dónde quedaría la libertad de escoger entre una u otra religión?

Por otra parte, Flew critica a Mitchell por la comparación que este hace de Dios con un extranjero, ya que si lo consideramos como tal, tendríamos que concluir que Dios no es omnipotente ni omnisciente 5 . Asimismo, dado que a Flew lo único que le interesa es la verificación intrahistórica, que no refiera a un más allá, él podría criticar las posiciones de Hick, Crombie y Ryle por considerar la verificación escatológica. Sin embargo, estaríamos de acuerdo con lo que opina Pannenberg: no es posible prescindir de la verificación escatológica, ya que si lo

5 "En tiempo de guerra en un país ocupado, un miembro de la resistencia se encuentra en una noche a un extranjero que le impresiona profundamente. Pasan esa noche juntos de conversación. El extranjero le cuenta al partisano que él mismo está del lado de la resistencia -en verdad, que está al mando de ella, y urge al partisano a tener fe en él sin importar lo que suceda-. El partisano queda enteramente convencido en el encuentro de la sinceridad y fidelidad del extranjero y se compromete a confiar en él. Nunca se encuentran de nuevo en condiciones de intimidad. Pero a veces el extranjero es visto ayudando a miembros de la resistencia y el partisano está agradecido y dice a sus amigos: "está de nuestro lado". A veces es visto con el uniforme de la policía entregando patriotas al poder de la ocupación. En estas ocasiones sus amigos murmuran contra él; pero el partisano, no obstante, dice: "está de nuestro lado". Él aún cree que, pese a las apariencias, el extranjero no le engañó. A veces pide ayuda al extranjero y la recibe. Entonces está agradecido. A veces le pide y no la recibe. Entonces dice: "El extranjero sabe lo mejor". A veces sus amigos, exasperados, dicen: "Bien, ¿qué tendría que hacer para que admitas que estabas equivocado y que él no está de nuestro lado?”. Pero el partisano se niega a contestar. No consentirá en poner a prueba al extranjero. $Y$ a veces sus amigos se quejan: "Bien, si eso es lo que tú quieres decir con su estar de nuestro lado, cuanto antes se pase al otro lado tanto mejor" (Flew, 1992, pp. 55-56). 
hiciéramos, nunca llegaríamos a deducir conclusiones definitivas acerca del sentido total de la historia y de la posibilidad de referirnos a la veracidad de las aseveraciones religiosas. No obstante, no por ello, la postura de Flew se invalida, pues en últimas el conflicto no se presenta en la consideración de la teología como un campo unificado, sino en la posibilidad de garantizar o no la facticidad de tal campo. Así, la cuestión del desafío planteado por Flew sigue estando abierta.

\section{Conclusión}

COMO PUDIMOS VER EN LA SECCIÓN ANTERIOR, la polémica continúa, pues responder a la pregunta de si la creencias religiosas son o no razonables no puede ser contestada categóricamente con un sí o con un no. No podemos afirmar radicalmente que sí son razonables, porque habría "miles de cualificaciones" que mostrarían la muerte de cualquier aserción que hagamos de Dios. Tampoco podemos decir que no son razonables, ya que las expresiones religiosas sí admiten un significado. Este concierne al sentido global de la existencia. De igual manera, tampoco podemos estar radicalmente a favor o en contra de los que defiende o no una evidencia racional para las creencias, ya que quizá algunos aspectos de unos se complementen con los otros, puesto que no necesariamente se contradicen. Por ejemplo, Hick, al igual que Braithwaite y MacIntyre, consideran clave el tema de la autoridad de Cristo para dar respuesta al desafío de Flew; asimismo, Hick, Mitchell, Crombie y Lonergan, al igual que Hare, MacIntyre, Braithwaite y James, consideran relevante el aspecto de la confianza como parte constitutiva de la fe, con lo que se aclara que sí hay aspectos conmensurables entre ambos.

En síntesis, podemos contestar que las creencias religiosas son razonables en parte, porque, según, Wittgenstein cada lenguaje, incluyendo el religioso, tiene su propia lógica. Por tal motivo, debemos rechazar cualquier reduccionismo que haga de la religión un campo limitado a solo un aspecto de la vida, ya sea a actitudes, o comportamientos o modos de vida, o desde una mirada racional, puesto que cuando hablamos de las expresiones religiosas debemos referirnos al misterio. De este modo, los significados varían según el uso que se les dé, ya que dentro de una concepción un significado puede que sea falso, pero en otra concepción puede que este mismo sea verdadero. 
Así, un uso del lenguaje que los autores analíticos trabajan es el indirecto, según el cual el lenguaje que refiere a algo mediante la mediación de otra cosa. Es de este modo como la religión utiliza el lenguaje indirecto, por medio de parábolas, mitos, paradojas, símbolos, analogías, etc. Filósofos lingüistas como Flew, Mitchell, Hare, Hick y Ryle han intentado señalar los posibles significados y la manera como sea posible afirmar la verdad o falsedad de las expresiones religiosas. De esta forma, por ejemplo, la parábola esclarece la discusión entre los creyentes y no creyentes, que nos muestra lo ambiguo que es este mundo y lo imposible que es optar concluyentemente o por el teísmo o por el ateísmo, vía datos empíricos. Asimismo, las paradojas nos muestran que ciertas palabras serían contradictorias si se analizara el lenguaje fuera de su contexto humano, que puede darles un sentido global.

Aunque para los que defienden la postura de la carencia de la fundamentación racional para las creencias religiosas, que hace que la teología se invalide, esto no indica que la teología no tenga aún mucho qué decirnos pues, al fin y al cabo, esta pretende responder, indirectamente, el desafío de Flew. De este modo, la relación entre filosofía y teología debe seguir teniendo un aspecto importante para considerar, ya que se refiere, en últimas, a la relación entre fe y razón. Es decir, el sentido de las creencias religiosas debe ser abordado tanto por la filosofía como por la teología. Si una de ellas falta, creemos que no es posible comprender las expresiones religiosas en su globalidad.

\section{Referencias}

Antiseri. D. (1976). El problema del lenguaje religioso. (Trad. A. De la Fuente Adanez). Madrid: Ediciones cristiandad, S.L.

Braithwaite, R.B (1975). La naturaleza del creer. G. Phillips (Ed.), Conocimiento ycreencia (pp. 47-67). (Trad. F. Caracheo). México, D.F.: Fondo de Cultura Económica.

Clifford, W.K. (2003). The Ethics of Belief. L. Pojman (Ed.), Philosophy of Religion (pp. 363-367). USA: Wadsworth/Thomson.

Crombie.I.M.(1992).Laposibilidad delosenunciadosteológicos.E.Romerales(Ed.), Creencia y racionalidad (pp. 61-99). Madrid: Ánthropos. 
Evans, S. (2002). Reason and the Paradox. D. Conway (Ed.), Kierkegaard. Critical Assessments of Leading Philosophers. Vol. II (pp. 93-113). London: Routledge. Flew, A. (1976). Dios y la filosofía. (Trad. M. Pérez Rivas). Buenos Aires: El Ateneo. Flew, A. (1994). La presunción del ateísmo. T. Miethe \& A. Flew (Eds), ¿Existe Dios? El debate entre un creyente y un ateo (pp.19-49). (Trad. P. Linares). Madrid: Ediciones Cátedra S.A.

Flew, A. (1992). Teología y falsación. E. Romerales (Ed.), Creencia y racionalidad (pp. 47-51). Madrid: Ánthropos.

Hare, R. (1992). Teología y falsación. E. Romerales (Ed.), Creencia y racionalidad (pp. 51-55). Madrid: Ánthropos.

Hick, J. (1964). The Existence of God. New York: The Macmillan Company.

Hick,J. (1992). Teología y verificación. E. Romerales (Ed.). Creencia y racionalidad (pp. 101-124). Madrid: Ánthropos.

Hume, D. (1981). Tratado de la naturaleza humana. (Trad. F. Duque). Madrid: Editora Nacional.

Hume, D. (1983). Investigación sobre el conocimiento humano. (Trad. J. De Salas Ortueta). Madrid: Alianza Editorial.

James, G. (s. f.). La voluntad de creer. (Trad. A. Conca). Buenos Aires: Editorial Tor. Kant, I. (2006). Crítica de la razón pura. (Trad. P. Ribas). México: Edición Taurus. Kierkegaard, S. (2000). Concluding Unscientific Postscript to Philosophical Fragments. H. Howard (Ed.), The Essential Kierkegaard (pp. 186-246). New Jersey: Princeton University Press.

Lonergan, B. (1994). Método en teología. (Trad. G. Remolina). Salamanca: Ediciones Sígueme, S.A.

MacIntyre, A. (1958). Visions. A. Flew \& A. MacIntyre (Ed), New essays in Philosophical Theology. (pp. 254-260). Londres: SCM PRESS LTD.

Mitchell, B. (1992). Teología y falsación. E. Romerales (Ed.), Creencia y racionalidad (pp. 55-57). Madrid: Ánthropos.

Pannenberg, W. (1981). Teoría de la ciencia y teología. (Trad. E. Rodríguez Navarro). Madrid: Libros Europa.

Pascal, B. (1984). Pensamientos. (Trad. E.D. Ors). Colombia: Editorial Oveja negra. 
Phillips, D. (1992). Creencias religiosas y juegos del lenguaje. E. Romerales (Ed.), Creencia y racionalidad (pp. 189-217). Madrid: Ánthropos.

Phillips, G. (1975). Conocimiento y creencia. (Trad. F. Caracheo). México, D.F.: Fondo de Cultura Económica.

Plantinga, A. (1992). Racionalidad y creencia. E. Romerales (Ed.), Creencia y racionalidad (pp. 237-267). Madrid: Ánthropos.

Platón. (1999). Teeteto. (Trad. A. Vallejo). Madrid: Editorial Planeta De Agostini. Pojman, L. (2003). Philosophy of Religion. USA: Wadsworth.

Popper, K. (2004). La lógica de la investigación cientifica. (Trad. V. Sánchez de Savala). Madrid: Tecnos.

Prichard, H.A. (1975). Conocer y creer. G. Phillips (Ed.), Conocimiento y creencia (pp. 96-108). (Trad. F. Caracheo). México, D.F.: Fondo de Cultura Económica. Quinn, P. (1992). En busca de los fundamentos del teísmo. E. Romerales (Ed.), Creencia y racionalidad (pp. 269-294). Madrid: Ánthropos.

Ryle, G. (1967). El concepto de lo mental. (Trad. E. Rabossi). Buenos Aires: Editorial Paidós.

Stewart, D. (1998). Exploring the Philosophy of Religion. USA: Prentice Hall. Villoro, L. (1982). Creer, saber, conocer. México: Siglo veintiuno editores.

Wittgenstein, L. (2005). Tractatus logico-philosophicus. (Trad. J. Muñoz e I. Reguera). Madrid: Alianza Editorial. Madrid.

Wittgenstein, L. (1992). Lecciones y conversaciones sobre estética, psicología y creencia religiosa. (Trad. I. Reguera). España: Paidós.

Wittgenstein, L. (1998). Investigaciones filosóficas. (Trad. A. García Suárez y U. Moulines). Barcelona: Crítica.

Wittgenstein, L. (2000). Sobre la certeza. (Trad. J. Prades y V. Raga). Barcelona: Editorial Gedisa.

Wittgenstein, L. (1989). Conferencia sobre ética. (Trad. F. Birulés). Barcelona: Paidós.

Wittgenstein, L. (1982). Diario filosófico. (Trad.J. Muñoze I. Reguera). Barcelona: Ariel. Barcelona. 